\title{
Atorvastatin reverses the dysfunction of human umbilical vein endothelial cells induced by angiotensin II
}

\author{
HAIMING DANG, BANGRONG SONG, RAN DONG and HONGJIA ZHANG
}

Department of Cardiac Surgery, Beijing Anzhen Hospital, Capital Medical University, Chaoyang, Beijing 100029, P.R. China

Received April 18, 2018; Accepted August 22, 2018

DOI: $10.3892 /$ etm.2018.6846

\begin{abstract}
Statins exert pleiotropic effects on endothelial cells, in addition to lowering cholesterol. This study evaluated angiotensin II (Ang II)-induced dysfunction in human umbilical vein endothelial cells (HUVECs), and the effects of atorvastatin (Ator) on induced HUVECs in vitro. The cytotoxicity of Ang II and Ator was determined by the MTT assay. A series of cellular responses were screened, including oxidative stress, cellular apoptosis, inflammatory response, autophagy, expression of endothelial nitric oxide synthase and the angiogenic function of HUVECs. Ator returned these cellular responses to a normal level. The present study also examined cellular organelle dysfunction. In HUVECs, Ang II triggered mitochondrial damage, as demonstrated by a decreased mitochondrial membrane potential, while Ator attenuated this Ang II-induced damage. The observed cellular dysfunction may cause endothelial senescence due to excessive cell injury. The current study examined several aging markers, which revealed that these disorders of cellular functions triggered endothelial senescence, which was delayed by Ator. Ator also suppressed Ang II-induced angiogenesis damage. The data presented in this study strongly suggested that Ang II induced a series of processes that lead to cellular dysfunction in HUVECs, including oxidative stress, inflammation, and mitochondrial damage, leading to apoptosis and endothelial senescence. However, Ator significantly reversed these effects and modulated intracellular stability. The present study indicated that Ator serves an antagonistic role against HUVEC dysfunction and may potentially prevent several diseases, including coronary disease and atherosclerosis, by maintaining cellular homeostasis.
\end{abstract}

Correspondence to: Dr Hongjia Zhang, Department of Cardiac Surgery, Beijing Anzhen Hospital, Capital Medical University, 2 Anzhen Road, Chaoyang, Beijing 100029, P.R. China

E-mail: dongr666@sina.com

Key words: atorvastatin, human umbilical vein endothelial cells, cellular dysfunction, homeostasis

\section{Introduction}

The renin-angiotensin-aldosterone system serves a role in the pathogenesis of cardiovascular diseases, including hypertension and atherosclerosis (1). Angiotensin II (Ang II) is the main active peptide hormone of the renin-angiotensin-aldosterone system (2). It serves a role in endothelial dysfunction, vascular remodeling and vascular inflammation, which are closely associated with numerous diseases, including hypertension and atherosclerosis $(3,4)$. Previous studies found that Ang II triggers a large amount of reactive oxygen species (ROS) in several human cell lines and organic tissues $(5,6)$. High levels of ROS can lead to mitochondrial dysfunction, inflammation and/or autophagy (7-9). These cellular responses are widely reported to cause disordered homeostasis in cells, ultimately leading to cell death (10-13).

Statins typically include lipophilic (simvastatin and atorvastatin) and hydrophilic (rosuvastatin) members (14). Atorvastatin (Ator) lowers the level of cholesterol in the blood by inhibiting 3-hydroxy-3-methylglutaryl-coenzyme A reductase, an enzyme with a key role in cholesterol production (15). Previous reports indicated a number of protective functions associated with Ator in cell lines, including the upregulation of endothelial nitric oxide expression and antioxidant effects $(16,17)$. Previous studies have also demonstrated the anti-hypertensive effects of Ator, promoting the resumption of endothelial function and via intrinsic anti-oxidant activities (18). There is evidence that high levels of ROS and cellular apoptosis are associated with senescence (19). Ator was previously reported to delay aging in endothelial progenitor cells (20). However, few studies have investigated the underlying mechanism by which Ator regulates endothelial function and senescence.

The present study screened the effects of Ator on Ang II-induced cytotoxicity in human umbilical vein endothelial cells (HUVECs). This study examined several cellular responses induced by Ang II, including oxidative stress, inflammation, autophagy and cell apoptosis, and determined whether Ator could reverse these changes. In addition, endothelial nitric oxide synthase (eNOS) protein expression was detected following exposure to Ang II alone and in combination with Ator, and this was shown to be associated with HUVEC function. The tube formation assay was performed to determine whether Ator influenced the angiogenic damage induced by treatment with Ang II. Furthermore, this study 
examined whether Ator was able to attenuate Ang II-induced senescence in HUVECs.

\section{Materials and methods}

Materials. Ang II was purchased from Sigma-Aldrich (Merck KGaA, Darmstadt, Germany). Ator was purchased from Pfizer, Inc. (New York, NY,USA). 3-(4,5-dimethylthiazol-2-yl)-2,5-diphenyl tetrazolium bromide (MTT), ROS Detection kit, Senescence-associated $\beta$-Galactosidase (SA- $\beta$-gal) staining kit, Rhodamine 123 (Rh123) Staining kit and Terminal deoxynucleotidyl-transferase-mediated dUTP nick-end labeling (TUNEL) Staining kit were purchased from Beyotime Institute of Biotechnology (Jiangsu, China). Anti-B-cell lymphoma 2 (BCL-2), anti-Bcl-2-associated X (BAX), anti-caspase-3 and anti-GAPDH antibodies were purchased from Santa Cruz Biotechnology, Inc. (Dallas, TX, USA). Anti-microtubule-associated protein 1A/1B-light chain 3 (LC3)-II, anti-LC3-I, anti-Beclin 1, anti-sequestosome 1 (p62), anti-endothelial nitric oxide synthase (eNOS), anti-tumor protein p53 (p53) and anti-cyclin dependent kinase inhibitor 2A (p16) antibodies were purchased from Cell Signaling Technology, Inc. (Danvers, MA, USA). The Chemicon ${ }^{\circledR}$ in vitro Angiogenesis Assay kit was obtained from Merck KGaA. Human interleukin (IL)-12 (cat. no. EK0421), IL-6 (cat. no. EK0410), IL-1 $\beta$ (cat. no. EK0932) and tumor necrosis factor- $\alpha$ (TNF- $\alpha$; cat. no. EK0525) ELISA kits were supplied by Boster Biological Technology (Pleasanton, CA, USA).

Cell culture. HUVECs were obtained from the Cell Bank of the Chinese Academy of Science (Shanghai, China; cat. no. H082). Cells were cultured in Dulbecco's modified Eagle's medium (DMEM; Invitrogen) supplemented with 10\% heat-inactivated fetal bovine serum (FBS) and 1\% penicillin-streptomycin (all Thermo Fisher Scientific, Inc., Waltham, MA, USA) at $37^{\circ} \mathrm{C}$ in a $5 \% \mathrm{CO}_{2}$-humidified incubator.

MTT assay. HUVECs were seeded onto 96 -well plates at a density of $1 \times 10^{4}$ cells/well and grown for $24 \mathrm{~h}$. In the first stage, the medium was replaced with medium containing different concentrations $(0.1,1,10$ or $100 \mu \mathrm{M})$ of Ang II (Sigma-Aldrich; Merck KGaA), and further incubated at $37^{\circ} \mathrm{C}$ for 24,48 and $72 \mathrm{~h}$. In the second stage, cells were incubated with fresh medium containing Ang II $(1 \mu \mathrm{M})$ alone or combined with various concentrations of atorvastatin $(1,10$, 20 or $50 \mu \mathrm{M})$ at $37^{\circ} \mathrm{C}$ for $24 \mathrm{~h}$. The effects of atorvastatin $(1$, $10,20$ or $50 \mu \mathrm{M})$ on cell viability were also examined. Cells were washed twice with phosphate-buffered saline and MTT was added to a final concentration of $0.5 \mathrm{mg} / \mathrm{ml}$ in each well and incubated for $4 \mathrm{~h}$ at $37^{\circ} \mathrm{C}$. Following MTT incubation, dimethylsulfoxide solution was used to dissolve the formazan crystals and absorbance was measured at a wavelength of $490 \mathrm{~nm}$ on a microplate reader (Thermo Multiskan MK3; Thermo Fisher Scientific, Inc.). The viability of control cells was set as $100 \%$.

ROS detection assay. ROS levels were determined by 2',7'-dichlorofluorescein diacetate assay (Beyotime Institute of Biotechnology), according to the manufacturer's protocol. Cells were seeded onto six-well plates at a density of $2 \times 10^{5}$ cells per well and grown for $24 \mathrm{~h}$. Subsequently, cells were treated with fresh DMEM containing $10 \mu \mathrm{M}$ Ator alone, 1- $\mu \mathrm{M}$ Ang II alone or combined with $10 \mu \mathrm{M}$ Ator at $37^{\circ} \mathrm{C}$ for $24 \mathrm{~h}$. A single treatment of $10 \mu \mathrm{M}$ Ator was also applied. Flow cytometry was performed to quantify the levels of ROS using a Cyan-LX instrument (Dako; Agilent Technologies, Inc., Santa Clara, CA, USA) and analyzed by FlowJo V10 CL software (FlowJo LLC, Ashland, OR, USA). The mean fluorescence was determined by counting 10,000 events.

Cytokine quantification assay. HUVECs were treated with $10 \mu \mathrm{M}$ Ator alone and $1 \mu \mathrm{M}$ Ang II alone or combined with $10 \mu \mathrm{M}$ Ator, and incubated at $37^{\circ} \mathrm{C}$ for $24 \mathrm{~h}$. Following incubation, the supernatant was pipetted into 96 -well plates and analyzed for IL-12, IL-6, IL-1 $\beta$ and TNF- $\alpha$ expression using the Human IL-12, IL-6, IL-1 $\beta$ and TNF- $\alpha$ ELISA kits, according to the manufacturer's protocol. Absorbance was measured at $450 \mathrm{~nm}$ with a correction wavelength at $570 \mathrm{~nm}$. The bicinchoninic acid (BCA) protein assay was used to measure the total protein concentration in the supernatant. Cytokine levels were calculated from a standard curve for each sample.

Mitochondrial membrane potential (MMP) assay. MMP assay was performed using the Rh123 Staining kit, according to the manufacturer's protocol. HUVECs were seeded onto six-well plates at a density of $2 \times 10^{5}$ cells/well and grown for $24 \mathrm{~h}$. Cells were treated with $10 \mu \mathrm{M}$ Ator alone and $1 \mu \mathrm{M}$ Ang II alone or combined with $10 \mu \mathrm{M}$ Ator and incubated for $24 \mathrm{~h}$ at $37^{\circ} \mathrm{C}$. Cells were washed twice with PBS and stained with $10 \mu \mathrm{g} / \mathrm{ml} \mathrm{Rh} 123$ for $30 \mathrm{~min}$ at $37^{\circ} \mathrm{C}$. Subsequently, stained cells were collected and analyzed using a flow cytometer (DakoCytomation; Dako; Agilent Technologies, Inc.) to quantify the fluorescence intensities of the cells. Data were analyzed with FlowJo V10 CL software.

TUNEL assay. HUVECs were seeded onto six-well plates at a density of $2 \times 10^{5}$ cells/well and grown for $24 \mathrm{~h}$. Subsequently, cells were treated with $10 \mu \mathrm{M}$ Ator alone and $1 \mu \mathrm{M}$ Ang II alone or combined with $10 \mu \mathrm{M}$ Ator for $24 \mathrm{~h}$ at $37^{\circ} \mathrm{C}$. TUNEL staining was then performed according to the manufacturer's protocol.

SA- $\beta$-gal assay. HUVECs were seeded onto six-well plates at a density of $2 \times 10^{5}$ cells/well and grown for $24 \mathrm{~h}$. Subsequently, cells were treated with $10 \mu \mathrm{M}$ Ator alone and $1 \mu \mathrm{M}$ Ang II alone or combined with $10 \mu \mathrm{M}$ Ator for $24 \mathrm{~h}$ at $37^{\circ} \mathrm{C}$. Cells were stained using the SA- $\beta$-gal staining kit, according to the manufacturer's protocol. Images were obtained using an optical microscope (SOPTOP ICX41; Ningbo Sunny Instruments Co., Ltd., Ningbo, China) at a magnification of x200 and analyzed using ImageJ software (version 1.4.9; National Institute of Health, Bethesda, MD, USA).

Tube formation assay. Tube formation assays were performed using the Chemicon in vitro Angiogenesis Assay kit according to manufacturer's protocol. Tube formation assays were performed using 24-well plates precoated with Matrigel, which was stored for $24 \mathrm{~h}$ at $4^{\circ} \mathrm{C}$ before the experiment. The Matrigel was thawed and $200 \mu \mathrm{l}$ was added to a 24 -well plate. The plate was incubated for $30 \mathrm{~min}$ at $37^{\circ} \mathrm{C}$ to form a gel layer. 

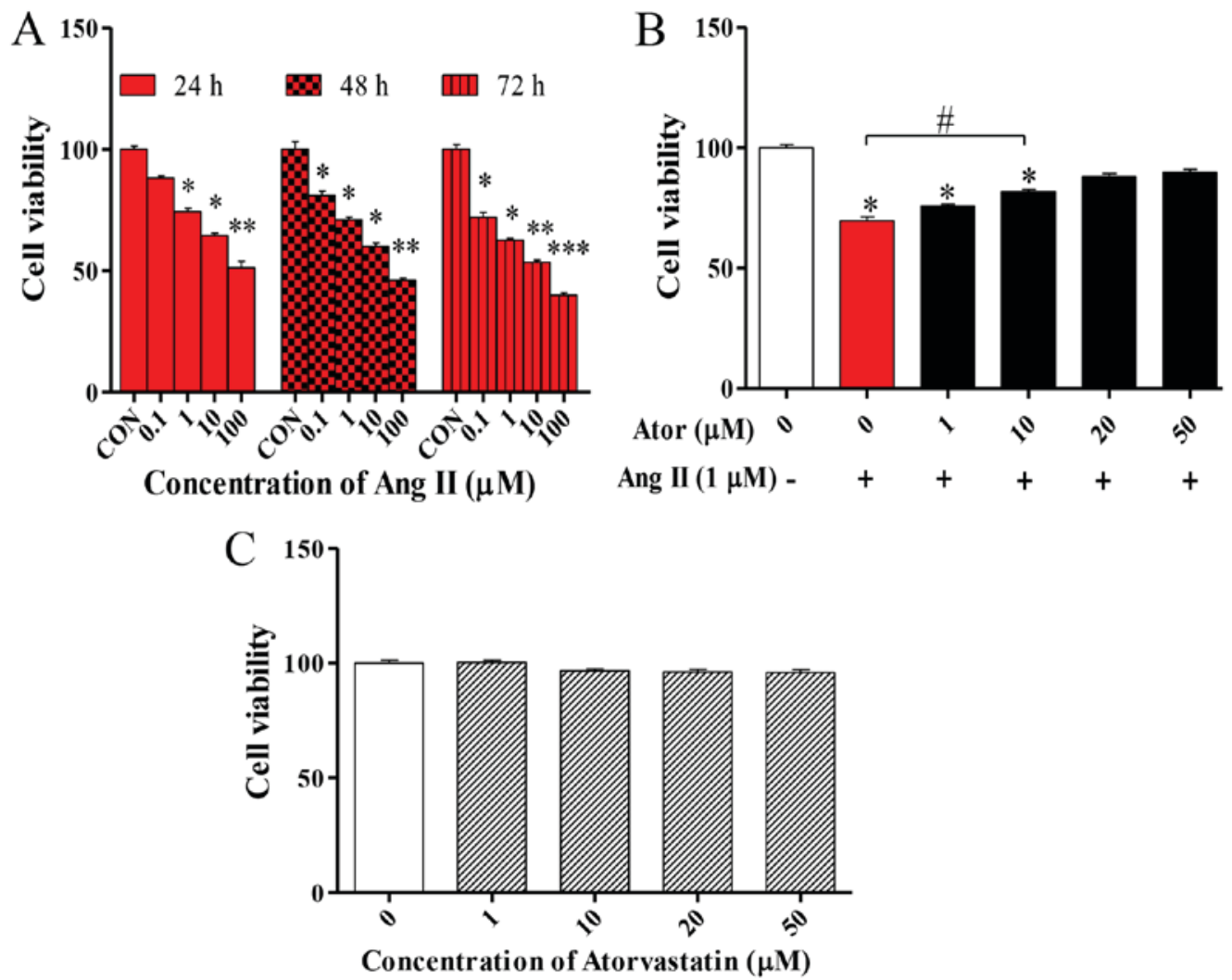

Figure 1. HUVEC viability. MTT assay was used to examine the viability of HUVECs following treatment with various concentrations of Ang II (A) alone or (B) in combination with Ator. (C) Cell viability was also assessed following treatment of HUVECs with various concentrations of Ator. Data are presented as the mean \pm standard error of the mean and normalized to untreated control. ${ }^{*} \mathrm{P}<0.05,{ }^{* * *} \mathrm{P}<0.01$ and ${ }^{* * * *} \mathrm{P}<0.01$ vs. control group; ${ }^{*} \mathrm{P}<0.05$ as indicated. HUVECs, human umbilical vein endothelial cells; Ator, atorvastatin; Ang II, angiotensin II; CON, untreated control.

Cells seeded at a density of $1 \times 10^{4}$ cells/well were treated with $10 \mu \mathrm{M}$ Ator alone, and $1 \mu \mathrm{M}$ Ang II alone or a combined of the two at $37^{\circ} \mathrm{C}$ overnight. The cells $\left(1 \times 10^{4}\right.$ cells/well $)$ were then plated onto Matrigel pre-coated 24-well plates in DMEM supplemented with $10 \%$ FBS medium and incubated for $4 \mathrm{~h}$. Images were obtained using an SOPTOP ICX41 optical microscope at a magnification of x200 and analyzed using ImageJ software.

Western blot analysis. HUVECs were seeded onto six-well plates at a density of $2 \times 10^{5}$ cells/well and grown for $24 \mathrm{~h}$. Total protein was extracted from cells using radioimmunoprecipitation lysis buffer (Beyotime Institute of Biotechnology). The resultant mixture was centrifuged at $10,000 \mathrm{x} \mathrm{g}$ for $10 \mathrm{~min}$ at $4{ }^{\circ} \mathrm{C}$. Total protein was quantified using a BCA protein assay kit (Beyotime Institute of Biotechnology), according to the manufacturer's protocol. The proteins $(20 \mu \mathrm{g} / \mathrm{lane})$ were separated by SDS-PAGE, transferred onto a polyvinylidene difluoride membrane and blocked with $5 \%$ nonfat milk at room temperature for $2 \mathrm{~h}$. The membranes were incubated with primary antibodies against human BCL-2 (cat. no. SC509), BAX (cat. no. SC6236), caspase-3 (cat. no. SC271028) and GAPDH (cat. no. SC47724; all 1:400; Santa Cruz Biotechnology, Inc.), p38 (cat. no. 8690), LC3-II (cat. no. 2775), LC3-I (cat. no. 4108), Beclin 1 (cat. no. 3778), p62 (cat. no. 88588), eNOS (cat. no. 32027), p53 (cat. no. 2527) or p16 (cat. no. 80772; all 1:400; Cell Signaling Technology, Inc.) overnight at $4^{\circ} \mathrm{C}$. Following primary incubation, membranes were incubated with horseradish peroxidase-conjugated secondary antibodies (1:5,000; cat. no. A0201) for $2 \mathrm{~h}$ at room temperature. Protein bands were visualized with BeyoECL Plus (both Beyotime Institute of Biotechnology). Protein expression was quantified using ImageJ software and normalized to GAPDH.

Statistical analysis. The results are reported as the mean \pm standard error of the mean of at least three independent experiments. All the experimental data were analyzed using one-way analysis of variance with Bonferroni correction multiple testing. Statistical analyses were performed using GraphPad Prism software (version 6.0; GraphPad Software, Inc., La Jolla, CA, USA). ${ }^{*} \mathrm{P}<0.05$ was considered to indicate a statistically significant difference.

\section{Results}

Cell viability measurement. To determine the effect of Ang II in HUVECs, cell viability was examined using the MTT assay. The MTT assay was performed following treatment with various concentrations $(0,0.1,1,10$ or $100 \mu \mathrm{M})$ of Ang II at 24,48 and $72 \mathrm{~h}$. Ang II significantly decreased cell viability in what appears to be a dose- and time-dependent manner (Fig. 1A). Based on these results, the effect of Ator on the viability of HUVECs was analyzed. HUVECs were treated with $1 \mu \mathrm{M}$ Ang II in combination with various concentrations $(1,10,20$ or $50 \mu \mathrm{M})$ of Ator for $24 \mathrm{~h}$. Ator appeared to suppress cell death in a dose-dependent manner (Fig. 1B). HUVECs 

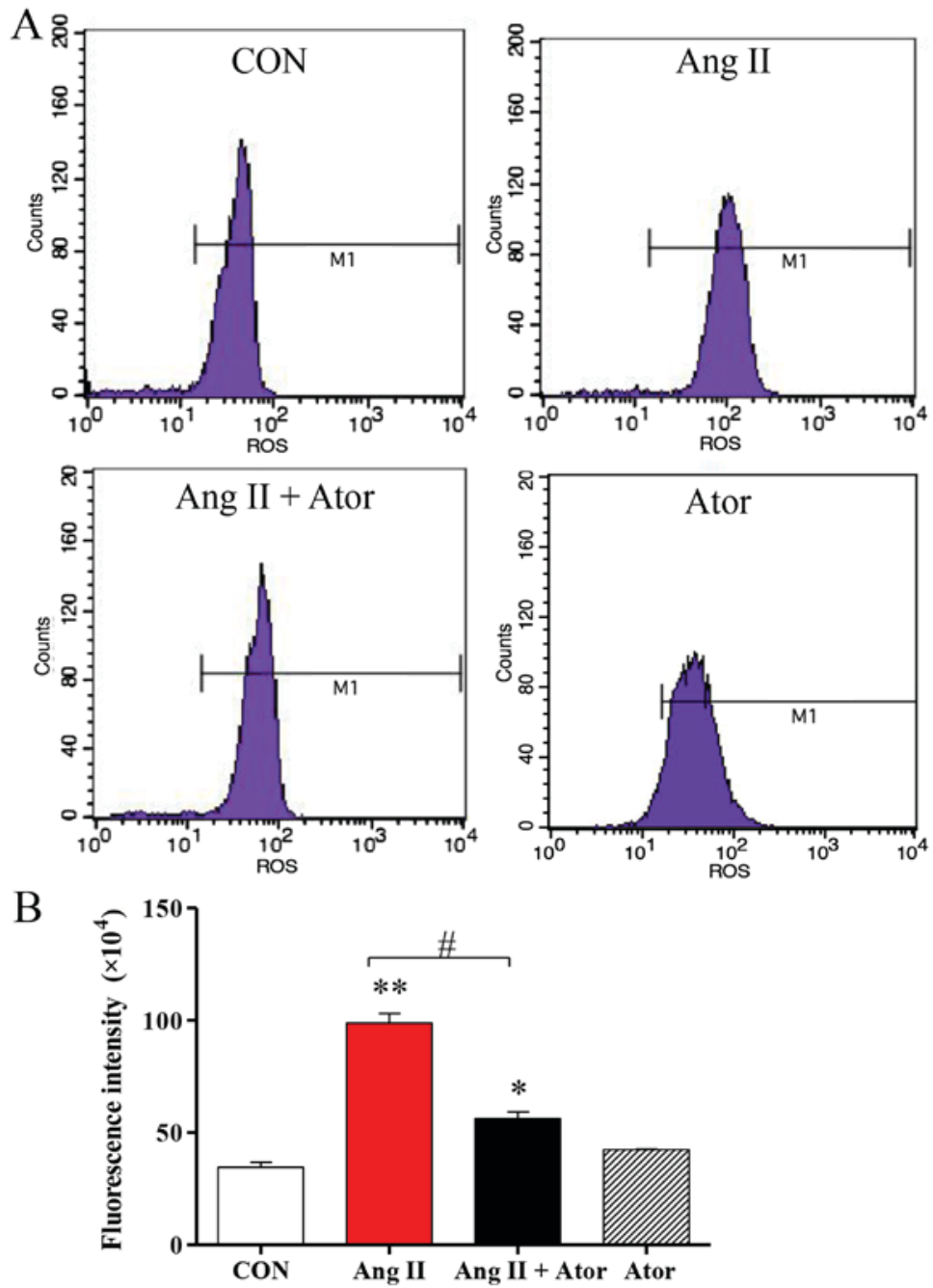

Figure 2. Ator attenuates Ang II-induced ROS levels in HUVECs. (A) Quantification of intracellular ROS levels in HUVECs was determined by flow cytometry, following treatment with Ang II, Ator or both. (B) Fluorescent intensity was calculated by multiplying the number of events by the mean of the fluorescence intensity value. Data are presented as the mean \pm standard error of the mean. ${ }^{*} \mathrm{P}<0.05$ and ${ }^{* * *} \mathrm{P}<0.01$ vs. control group; ${ }^{*} \mathrm{P}<0.05$ as indicated. ROS reactive oxygen species; CON, untreated control; Ator, atorvastatin; Ang II, angiotensin II; HUVECs, human umbilical vein endothelial cells.

were treated with various concentrations $(1,10,20$ or $50 \mu \mathrm{M})$ of Ator alone. Ator did not affect cell viability (Fig. 1C). These results indicated that Ator may be able to repair the cellular damage caused by Ang II and protect cells from death.

Ator attenuates Ang II-induced cytotoxicity in HUVECs. To monitor the effects of Ator on Ang II-induced cytotoxicity in HUVECs, several cellular processes were examined in this study. Intracellular levels of ROS were assessed using flow cytometry (Fig. 2A). ROS generation in HUVECs was significantly elevated following treatment with Ang II, compared with the untreated control. However, the addition of Ator significantly decreased intracellular ROS compared with the Ang II treatment group. Treatment with Ator alone did not cause any significant changes in ROS generation (Fig. 2B).

Mitochondria are one of the main sources of ROS under conditions of oxidative stress; elevated intracellular ROS may lead to mitochondrial dysfunction, an early indication of cell death (21). The present study analyzed the mitochondrial membrane potential by Rh123 staining. Rh123 is a fluorescent dye that accumulates in normal mitochondria. Intracellular Rh123 fluorescence was assessed using flow cytometry (Fig. 3A). Rh123 fluorescence was significantly weaker following treatment with Ang II, compared with the untreated control group. However, the fluorescent signal was attenuated in the presence of Ator compared with the Ang II alone treatment group. Treatment with Ator alone did not cause any obvious alterations compared with the untreated control (Fig. 3B). These results indicated that Ator suppressed cell death and prevented mitochondrial damage caused by Ang II.

Cell injury may trigger a chain reaction of inflammatory responses (22). The present study examined the inflammatory response to treatment with Ang II in HUVECs. Treatment with Ang II significantly increased intracellular inflammation, as indicated by enhanced IL-1 $\beta$, IL-12, TNF- $\alpha$ and IL- 6 cytokine expression levels, compared with the untreated control group. However, the addition of Ator decreased cytokine secretion compared with the Ang II treatment group. Treatment with Ator alone did not cause any significant changes to cytokine expression (Fig. 4). These results suggested that Ator prevented cells from chronic inflammation.

Autophagy is a fundamental cellular process in the degradation of cellular organelles (23). Due to the Ang II-induced mitochondrial damage observed, the effects of Ang II and Ator 

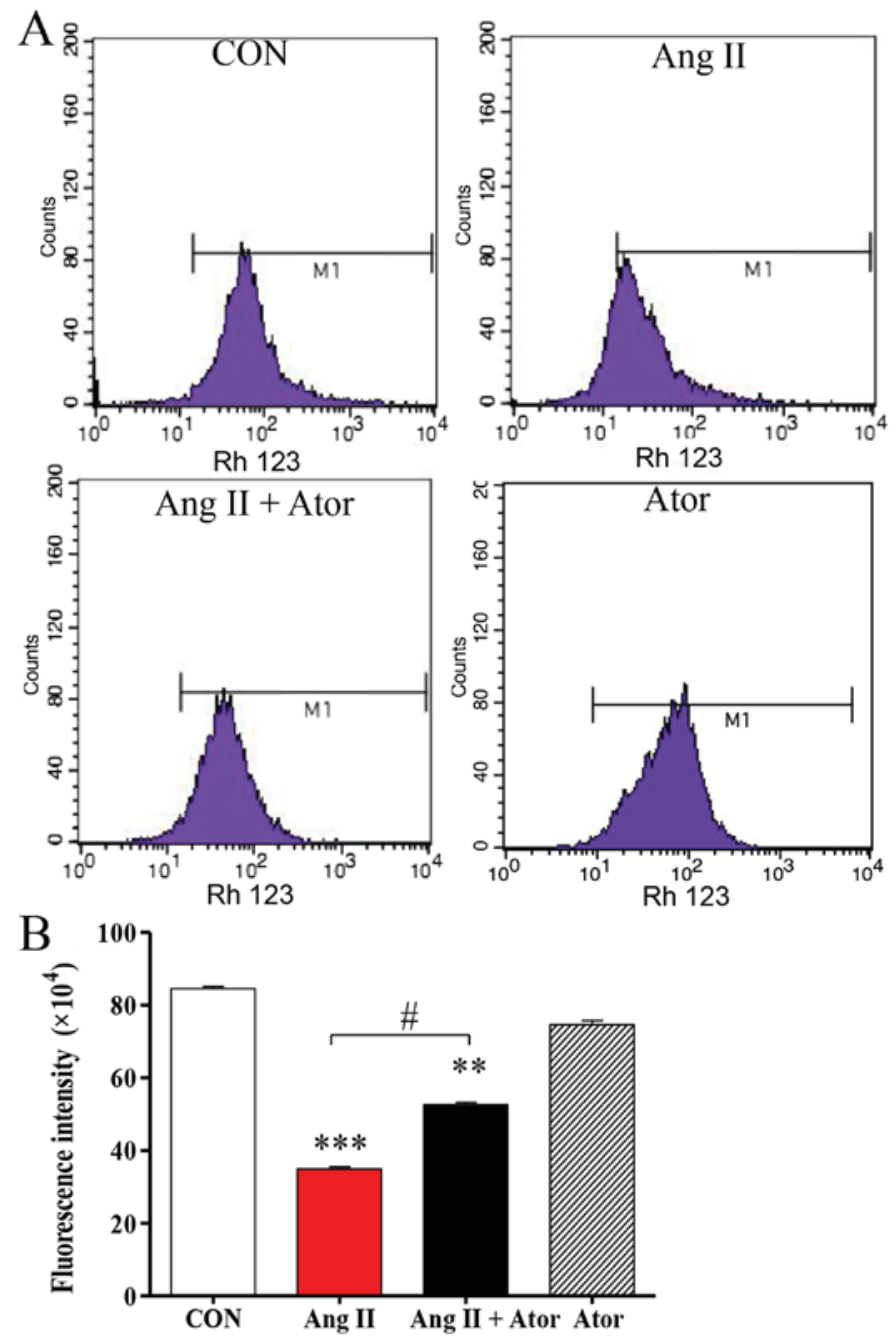

Figure 3. Ator attenuates Ang II-inhibits the mitochondrial membrane potential in HUVECs. (A) Quantification of mitochondrial membrane potential in HUVECs was determined by flow cytometry, following treatment with Ang II, Ator or both. (B) Fluorescent intensity was calculated by multiplying the number of events by the mean of the fluorescence intensity value. Data are presented as the mean \pm standard error of the mean. ${ }^{* *} \mathrm{P}<0.01$ and ${ }^{* * * *} \mathrm{P}<0.001$ vs. control group; ${ }^{\mathrm{P}}<0.05$ as indicated. HUVECs, human umbilical vein endothelial cells; CON, untreated control; Ator, atorvastatin; Ang II, angiotensin II.

on cell autophagy in HUVECs were analyzed. The exposure of HUVECs to treatment with Ang II significantly enhanced protein expression levels of LC3-II/-I (Fig. 5A). In addition, the protein level of Beclin 1, which is known to regulate autophagy via the Beclin 1/VPS34 complex was also significantly increased following treatment with Ang II. To further confirm autophagy, the protein level of p62, an important indicator of autophagic flux, was analyzed. Expression levels of p62 significantly increased following treatment with Ang II (Fig. 5A), indicating inhibition of the autophagic flux. The activation of autophagy and the suppression of autophagic flux can lead to LC3-II and autophagosome accumulation (24). The present study indicated that in HUVECs, the activation of autophagy and suppression of autophagic flux occur following treatment with Ang II. The induction of autophagy and the blockade of autophagy flux can lead to LC3II and autophagosome accumulation (24). The elevated levels of p62 suggested that Ang II may not only induce autophagic activity but also block autophagy flux (24). The addition of Ator significantly reversed Ang II-induced effects on the expression of autophagy-associated proteins (Fig. 5A). Treatment with Ator alone did not cause any significant alterations compared with the untreated control (Fig. 5B). The present study indicated that Ator attenuated Ang II-induced cellular autophagy, and this may be attributed to its effect on intracellular ROS generation.

To further investigate the effects of Ang II and Ator on HUVECs, cellular apoptosis was analyzed by the TUNEL assay. Cellular apoptosis was significantly increased following treatment with Ang II, however the addition of Ator markedly suppressed Ang II-induced apoptosis in HUVECs (Fig. 6A). Furthermore, treatment with Ang II significantly increased expression levels of cellular apoptosis-associated proteins BAX and caspase-3, and decreased the expression of BCL-2, compared with the untreated control group (Fig. 6B). The addition of Ator significantly reversed the effects of Ang II on the expression of cellular apoptosis-associated proteins. Treatment with Ator alone did not cause any significant alterations compared with the untreated control (Fig. 6C). This study indicated that Ator attenuated Ang II-induced cellular apoptosis.

Ator modulates eNOS expression in HUVECs. Injury can cause cellular dysfunction (25). To further investigate the biological functions of Ang II and Ator in HUVECs, protein expression 

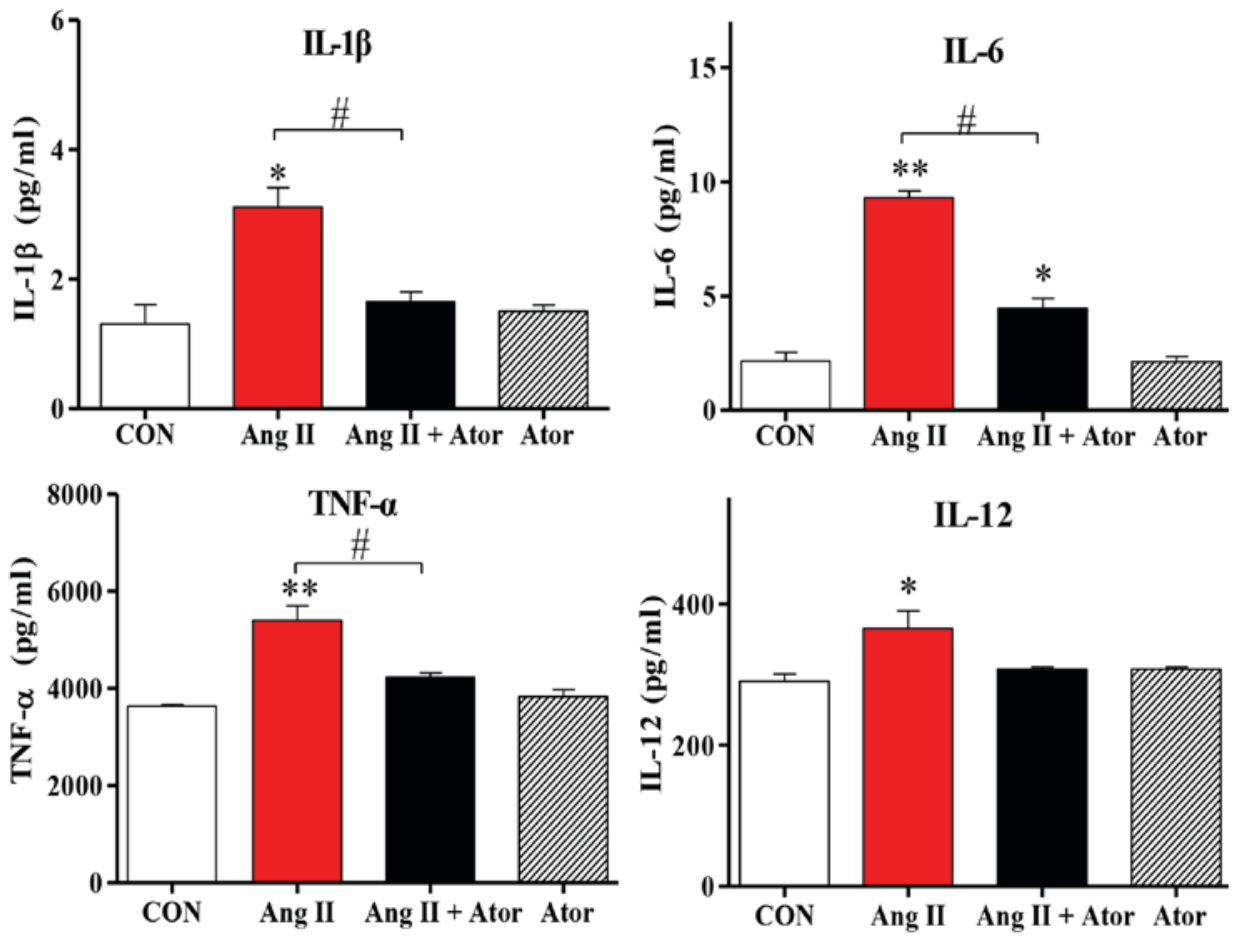

Figure 4. Ator attenuates inflammatory cytokine expression levels in HUVECs. The expression levels of various proteins implicated in pro-inflammatory responses were analyzed. The mRNA expression levels of interleukin (IL)-1 $\beta$, IL-6, TNF- $\alpha$ and IL-12 were determined following treatment with Ang II, Ator or both. Data are presented as the mean \pm standard error of the mean. ${ }^{*} \mathrm{P}<0.05$ and ${ }^{* *} \mathrm{P}<0.01$ vs. control group; ${ }^{*} \mathrm{P}<0.05$ as indicated. CON, untreated control; Ator, atorvastatin; Ang II, angiotensin II; IL, interleukin; TNF- $\alpha$, tumor necrosis factor- $\alpha$.
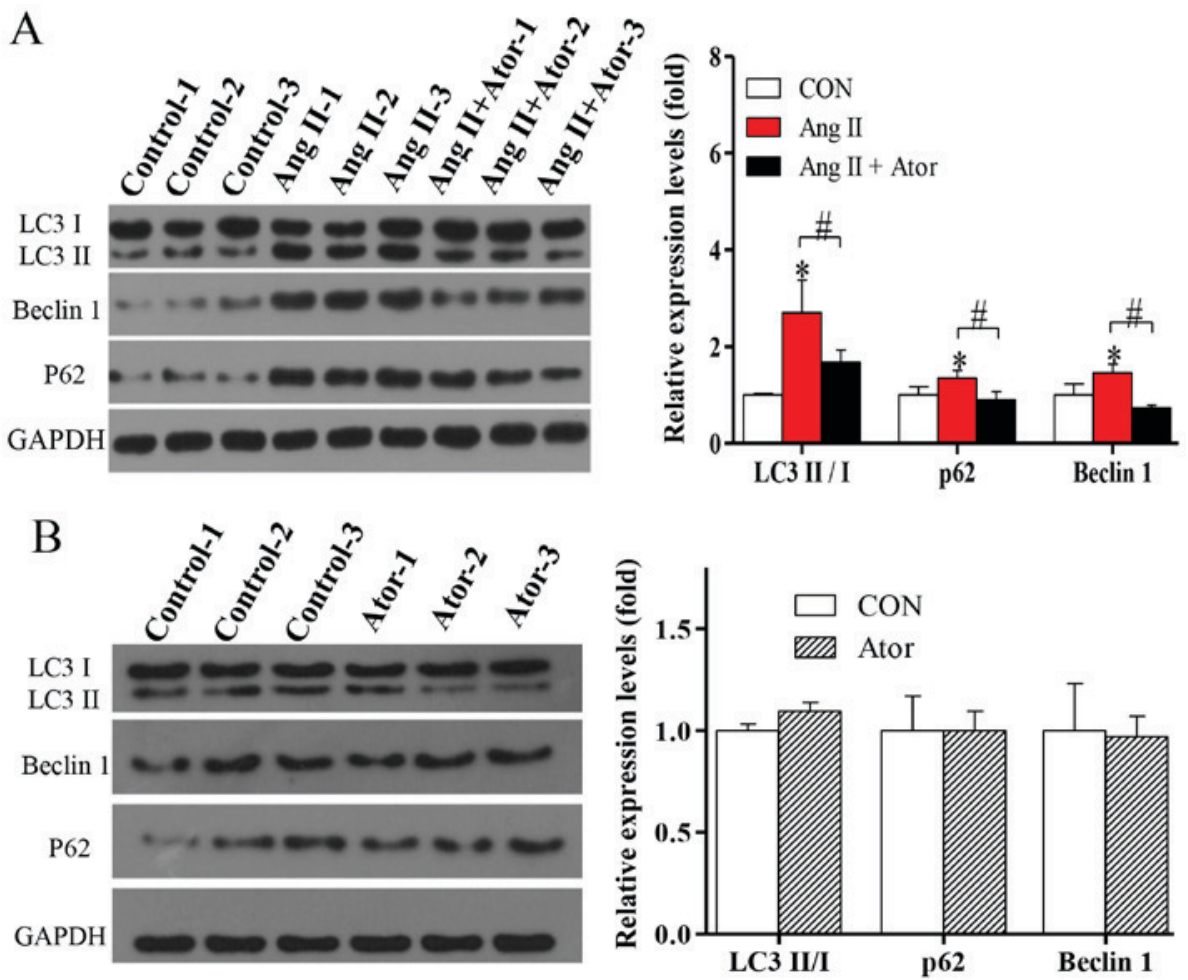

Figure 5. Ator attenuates autophagy dysfunction in HUVECs. The protein expression levels of LC3-II/I, Beclin 1 and p62 were determined using western blot analysis in HUVECs following treatment with (A) Ang II and Ang II + Ator or (B) Ator alone for $24 \mathrm{~h}$. GAPDH was used as the loading control. Data are presented as the mean \pm standard error of the mean. ${ }^{*} \mathrm{P}<0.05$ vs. control group; ${ }^{*} \mathrm{P}<0.05$ as indicated. HUVECs, human umbilical vein endothelial cells; CON, untreated control; Ator, atorvastatin; Ang II, angiotensin II; LC3, microtubule-associated protein 1A/1B-light chain 3.

level of eNOS, a key enzyme responsible for the proper function of the vascular endothelium (26), was analyzed by western blotting. Treatment with Ang II significantly decreased the expression level of eNOS, compared with the untreated control 

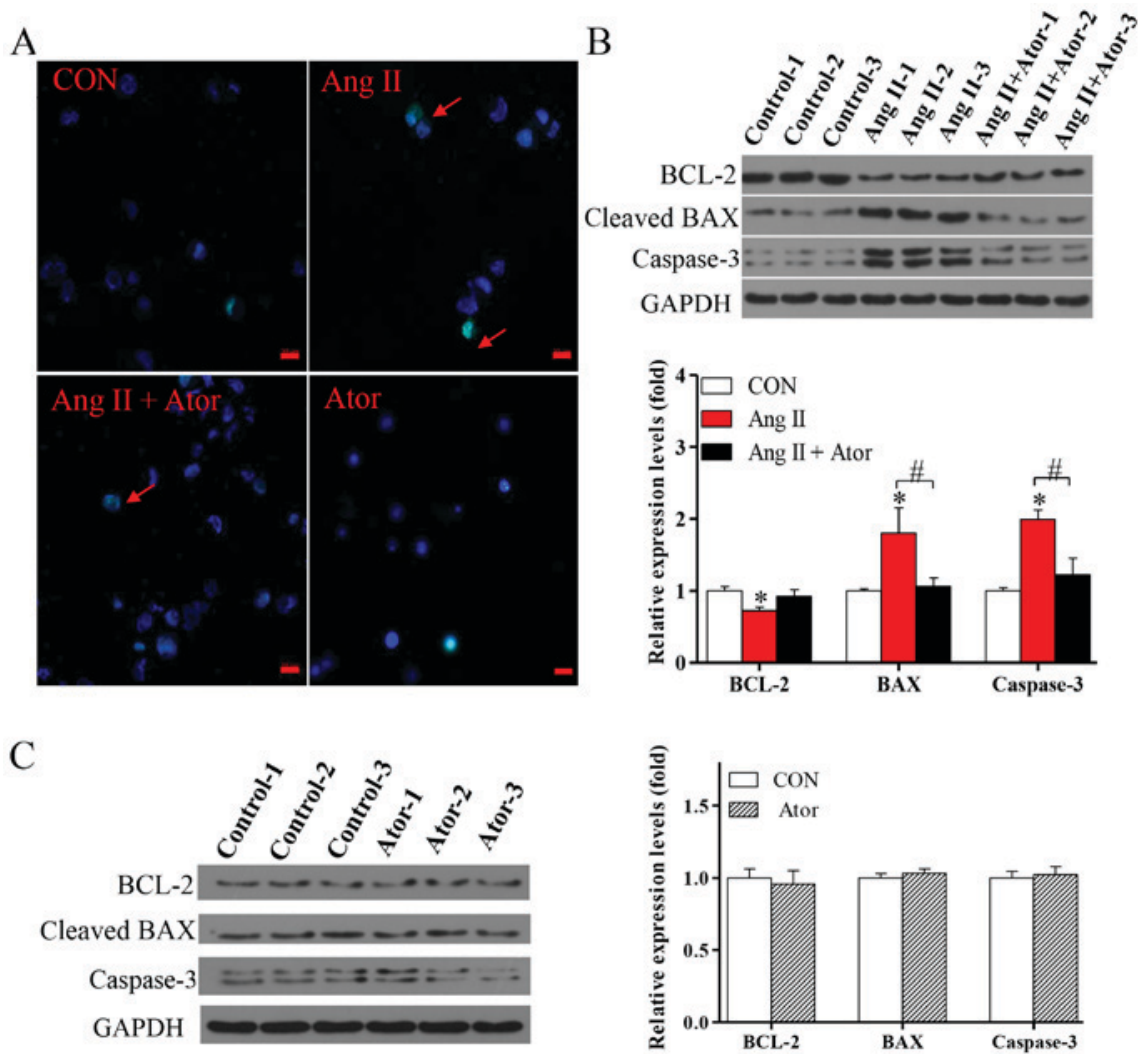

Figure 6. Ator attenuates cell apoptosis in HUVECs. (A) Terminal deoxynucleotidyl-transferase-mediated dUTP nick-end labeling assay was used to examine cell apoptosis in HUVECs following $24 \mathrm{~h}$ treatment with Ang II, Ator or both. Arrows indicate apoptotic cells. The protein expression levels of BCL-2, BAX and caspase-3 were determined using western blot analysis in HUVECs following treatment with (B) Ang II and Ang II + Ator or (C) Ator alone for $24 \mathrm{~h}$. GAPDH was used as the loading control. Scale bar, $20 \mu \mathrm{m}$. Data are presented as the mean \pm standard error of the mean, $\mathrm{n}=3$. ${ }^{*} \mathrm{P}<0.05$ vs. control group; ${ }^{*} \mathrm{P}<0.05$ as indicated. HUVECs, human umbilical vein endothelial cells; CON, untreated control; Ator, atorvastatin; Ang II, angiotensin II; LC3, microtubule-associated protein 1A/1B-light chain 3; BCL-2, B-cell lymphoma 2; BAX, Bcl-2-associated X.

group (Fig. 7). The addition of Ator significantly reversed the effects of Ang II on the expression of eNOS. Expression levels in HUVECs treated with Ator alone did not exhibit any significant changes compared with the untreated control (Fig. 7).

Ator delays aging in HUVECs. Apoptosis may enhance aging (19). To determine the effects of Ator on the process of aging in HUVECs, the expression levels of senescence-associated markers p53 and p16 were analyzed by western blotting. Treatment with Ang II significantly increased the expression levels of p53 and p16, compared with the untreated control. The addition of Ator significantly reversed the effect observed (Fig. 8A). Cells treated with Ator alone did not exhibit any significant changes, compared with the untreated control (Fig. 8A). These results indicated that Ang II-induced apoptosis may be associated with the process of cellular senescence, while Ator may be involved in delaying the aging process. To further investigate the process of aging in HUVECs, the level of SA- $\beta$-gal expression was analyzed by utilizing a commercial SA- $\beta$-gal staining kit. The proportion of senescent cells was significantly increased in HUVECs treated with Ang II (Fig. 8B). Following treatment with Ator, the proportion of senescent cells decreased significantly compared with the Ang II-only treatment group (Fig. 8B). These results are consistent with those for previously described senescence markers (27). In addition, HUVECs treated with Ator alone did not exhibit any significant changes in expression levels of the senescence-associated markers compared with the untreated control (Fig. 8B). Therefore, Ator reversed the aging induced by Ang II, exhibiting anti-aging activity.

Ator reverses Ang II-induced tube formation damage. HUVECs are the most widely used cell type used for studying vasculature and angiogenesis (28-30). Excessive damage to HUVECs may influence their biological function (31). The effect of Ang II and Ator on tube formation in HUVECs was analyzed by tube formation assay (Fig. 9A). The length of the tube-like vasculature of HUVECs was significantly shortened in response to treatment with Ang II, compared with the control group (Fig. 9B). However, the addition of Ator significantly reversed the effect observed with Ang II alone. Cells treated with Ator alone did not exhibit any obvious changes in length, compared with the untreated control (Fig. 9B). The present study demonstrated the ability of Ator to reverse Ang II-induced cellular dysfunction. A series of cellular responses, including oxidative stress, cellular apoptosis, inflammatory response, autophagy, expression of eNOS and the angiogenic function of HUVECs all returned to normal following treatment with Ator.

\section{Discussion}

As Ang II may cause damage to human umbilical vein endothelial cells (HUVECs), an MTT assay was performed to examine 

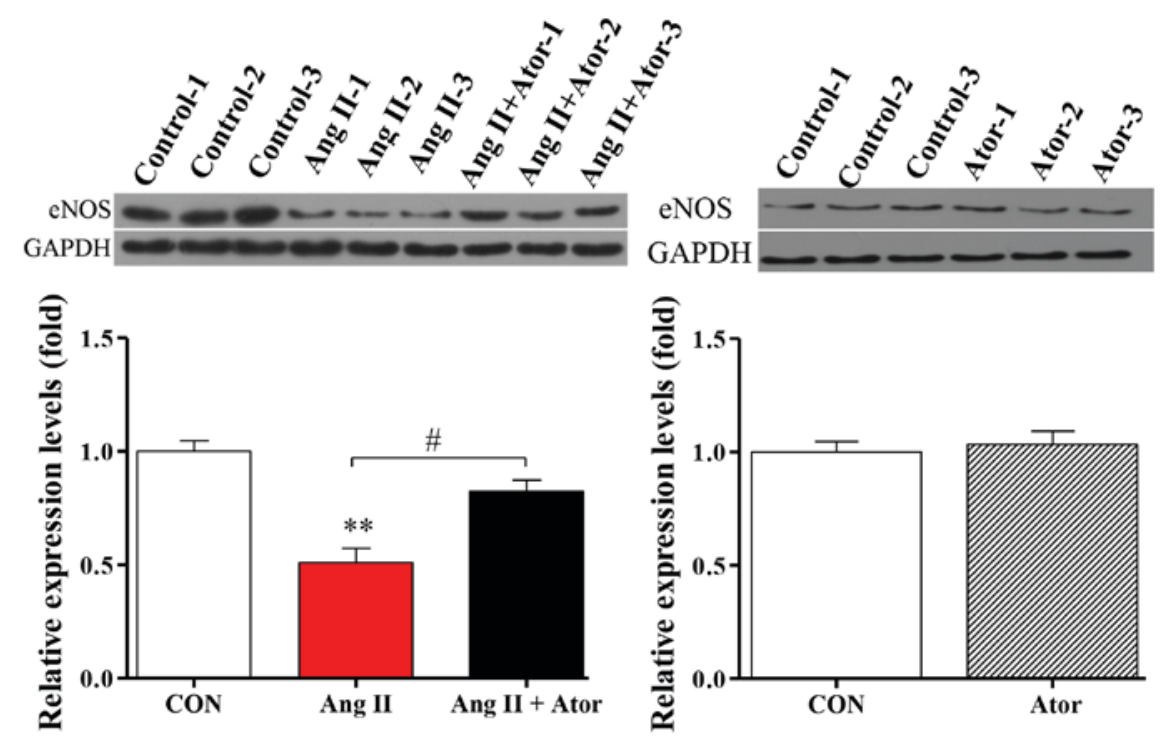

Figure 7. Ator modulates eNOS expression. The protein expression level of eNOS was determined using western blot analysis in HUVECs following treatment with Ang II, Ang II + Ator or Ator alone for $24 \mathrm{~h}$. GAPDH was used as the loading control. Data are presented as the mean \pm standard error of the mean. ${ }^{* *} \mathrm{P}<0.01$ vs. control group; ${ }^{*} \mathrm{P}<0.05$ as indicated. HUVECs, human umbilical vein endothelial cells; CON, untreated control; Ator, atorvastatin; Ang II, angiotensin II; LC3, microtubule-associated protein 1A/1B-light chain 3; eNOS, endothelial nitric oxide synthase.

A
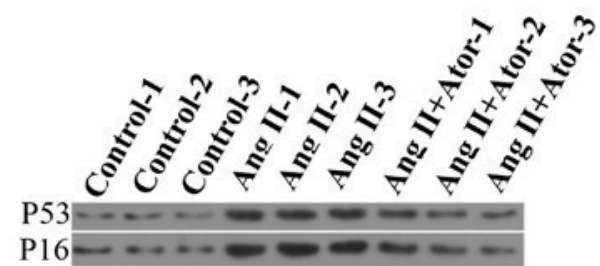

GAPDH

P53

P16

GAPDH
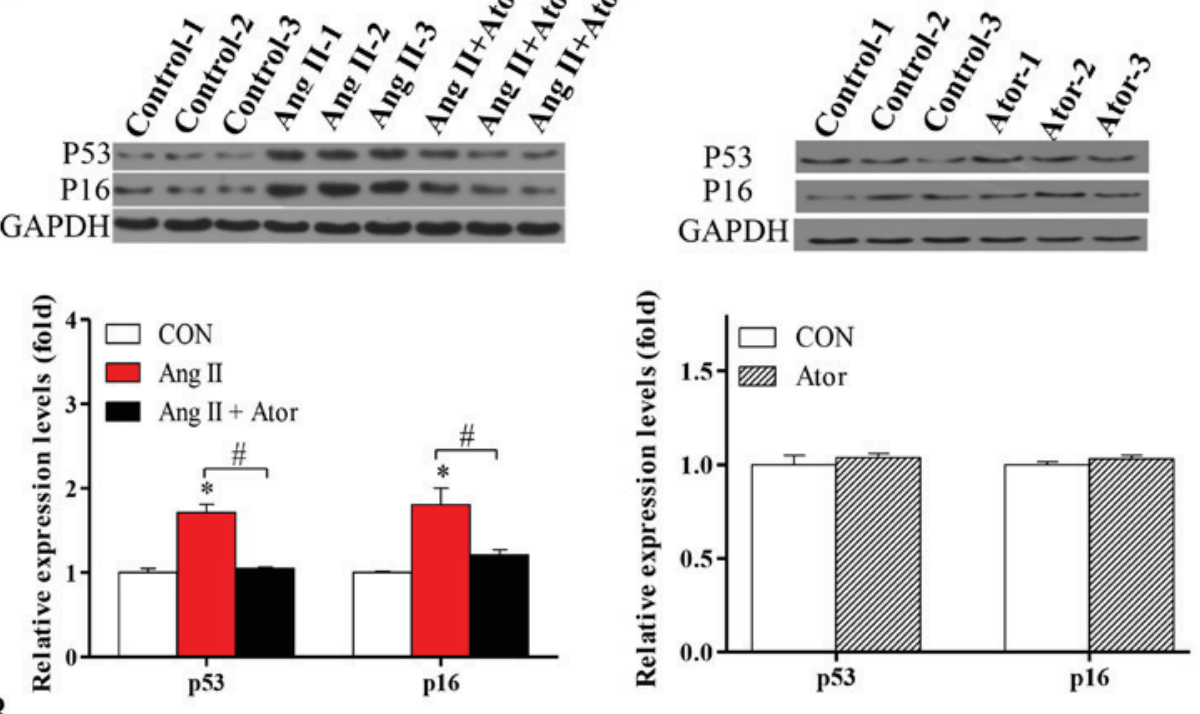

$\mathrm{B}$
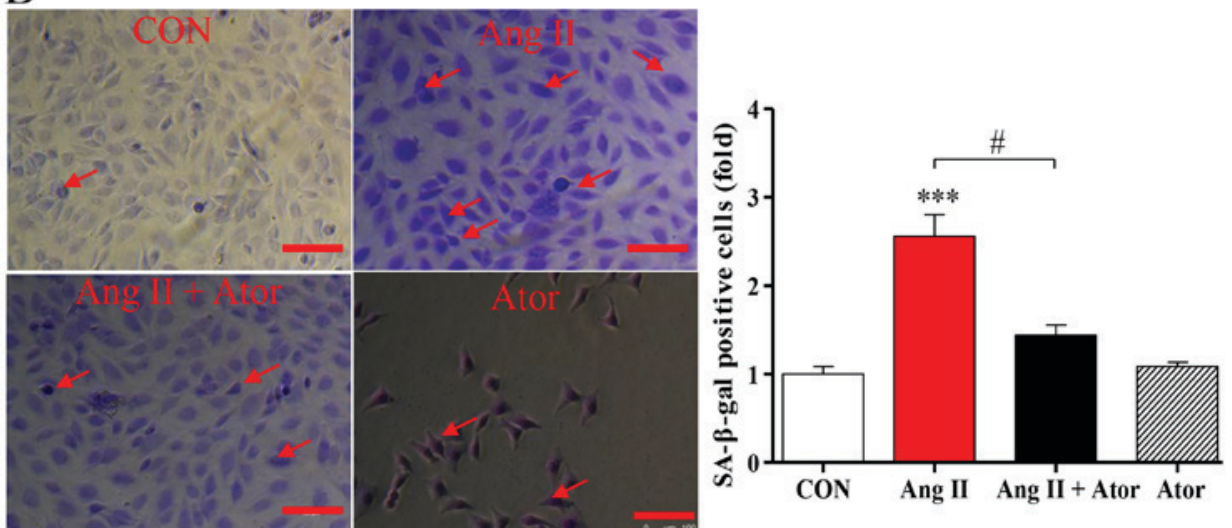

Figure 8. Ator suppresses Ang II-induced endothelial cell senescence. (A) The protein expression levels of p53 and p16 were determined using western blot analysis in HUVECs following treatment with Ang II, Ang II + Ator or Ator alone for $24 \mathrm{~h}$. GAPDH was used as the loading control. (B) SA- $\beta$-gal staining was used examine cell senescence in HUVECs following treatment with Ang II, Ang II + Ator or Ator alone for $24 \mathrm{~h}$. Arrows indicate senescent cells. Scale bar, $100 \mu \mathrm{m}$. Data are presented as the mean \pm standard error of the mean, $\mathrm{n}=3$. ${ }^{*} \mathrm{P}<0.05$ and ${ }^{* * * *} \mathrm{P}<0.001$ vs. control group; $\mathrm{P}<0.05$ as indicated. HUVECs, human umbilical vein endothelial cells; SA- $\beta$-gal, senescence-associated $\beta$-galactosidase; CON, control; Ator, atorvastatin; Ang II, angiotensin II. 

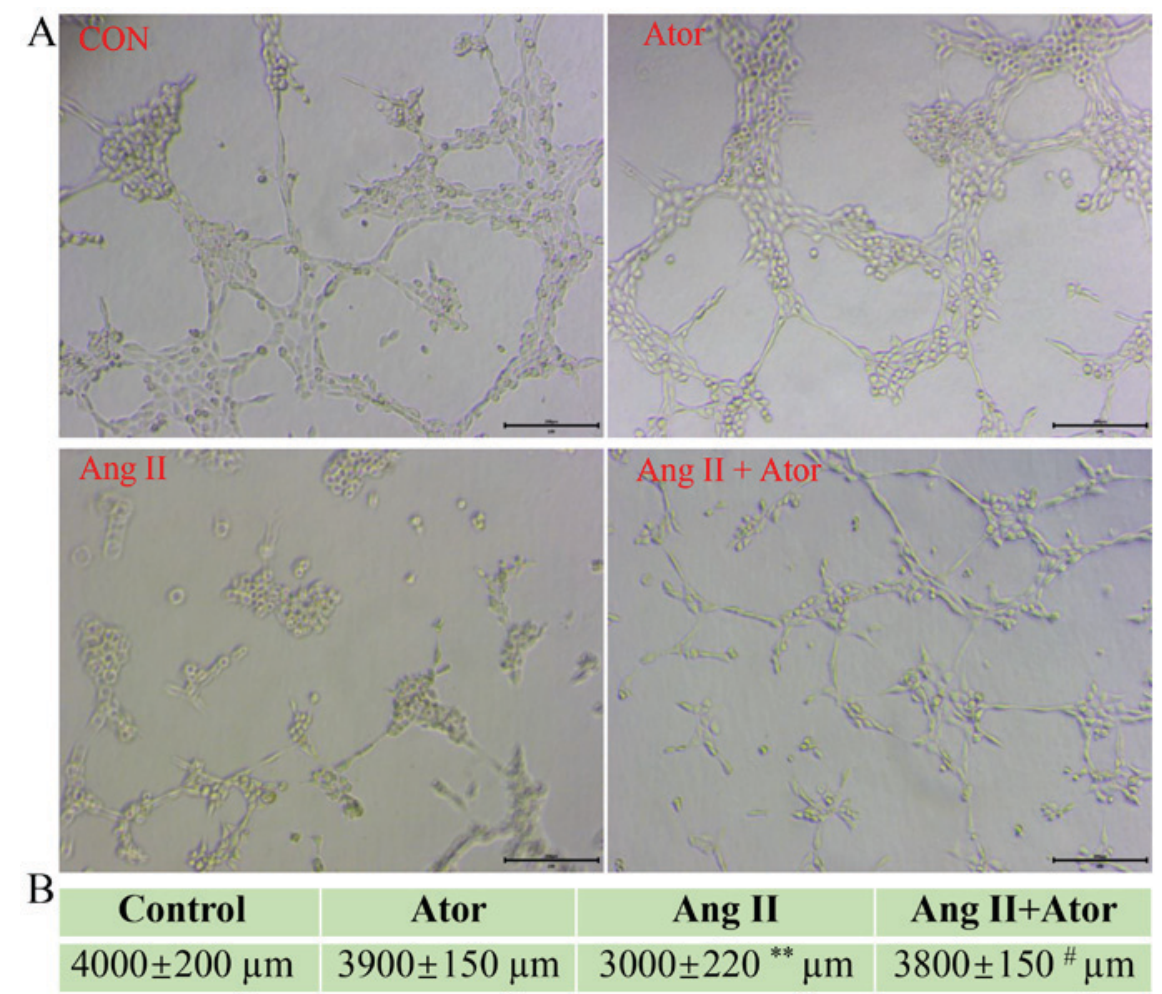

Figure 9. Ator reverses Ang II-induced tube formation damage. (A) Tube formation in HUVECs following treatment with Ang II, Ang II + Ator or Ator alone. (B) Total length of tube formation in HUVECs following treatment. Scale bar, $200 \mu \mathrm{m}$. Data are presented as the mean \pm standard error of the mean, $\mathrm{n}=3$. ${ }^{* *} \mathrm{P}<0.01$ vs. control group; ${ }^{*} \mathrm{P}<0.05$ vs. Ang II. HUVECs, human umbilical vein endothelial cells; CON, control; Ator, atorvastatin; Ang II, angiotensin II.

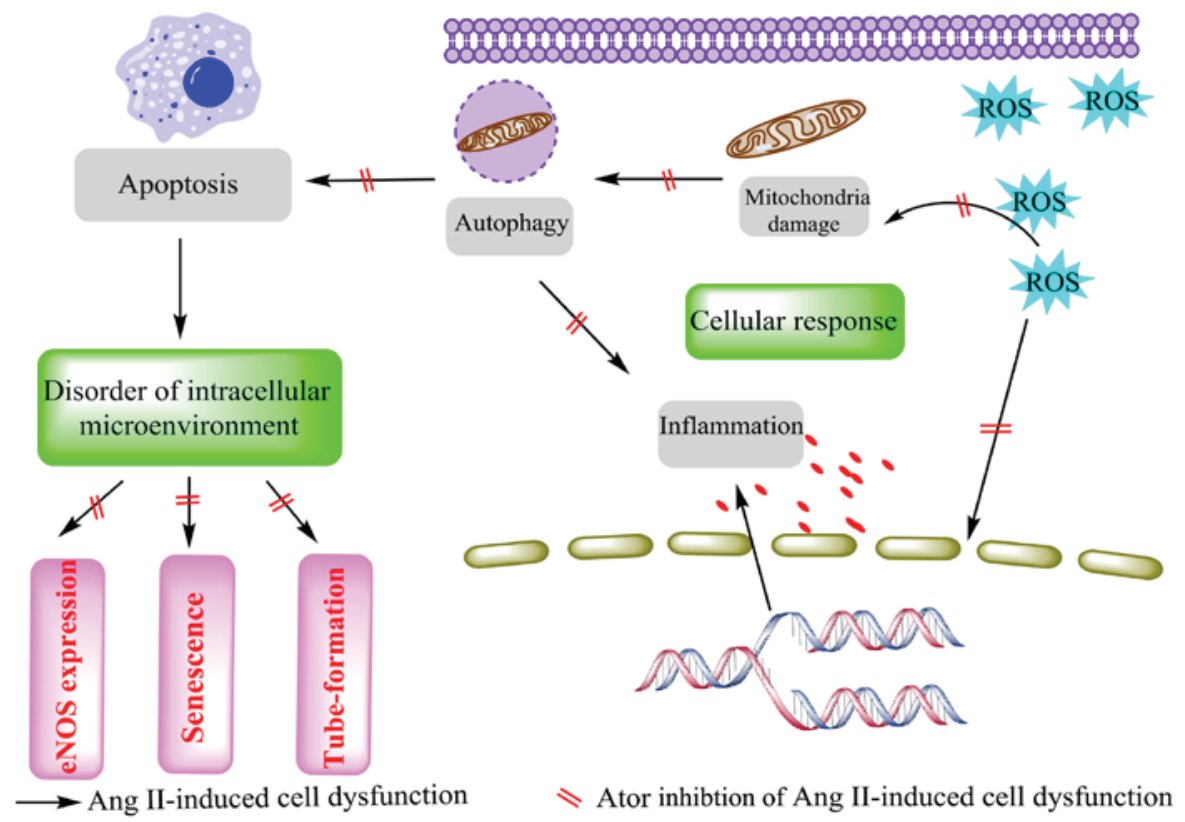

Figure 10. Ator attenuates Ang II-induced dysfunction of HUVECs. Ator, atorvastatin; Ang II, angiotensin II; HUVECs, human umbilical vein endothelial cells; ROS, reactive oxygen species; eNOS, endothelial nitric oxide synthase.

cell viability. Ang II significantly decreased HUVEC viability in a dose-dependent manner. However, Ator reversed the Ang II-induced cell death in a dose-dependent manner. These results demonstrated a critical role for Ator in Ang II-induced cell death in HUVECs. Several cellular responses were further examined in the present study, including oxidative stress, inflammatory response, MMP and autophagy.
ROS are well-known indicators of oxidative stress and their expression is associated with a number of cellular responses (7). Treatment with Ang II induced high levels of ROS, however not when combined with Ator treatment. Increased levels of ROS may target the cell membrane, mitochondrial membrane or intracellular biological molecules, causing cell damage and/or cell death (32). Mitochondria are one of the main sources of 
ROS under conditions of oxidative stress (21). An increasing number of reports have demonstrated that elevated ROS can attack mitochondria, causing mitochondrial damage (21). This study investigated the effects of Ang II and Ator on MMP, an important marker of mitochondrial function (33). Following treatment with Ang II, a significant decrease in MMP was observed and this decrease in MMP was attenuated by the addition of Ator. The current study revealed that exposure to Ang II caused mitochondrial stress, leading to a loss of mitochondrial function, which was partially reversed by the addition of Ator.

Ang II can induce chronic inflammation in cells (34). Although the inflammatory response may be important for preventing cell damage, chronic inflammation is harmful for living cells (35). The present study demonstrated that Ator attenuated Ang II-induced inflammation.

Homeostatic imbalance can lead to the activation of several signaling pathways for the prevention of cell damage or death. Autophagy is a well-known, regulated mechanism promoting the survival of cells under metabolic stress (36). During autophagy, LC3 protein is converted from its cytosolic form (LC3-I) into its enzymatic counterpart, LC3-II, which is recruited to autophagosomal membranes (24). In the present study, changes in LC3-II/I expression levels revealed that Ator reversed Ang II-induced autophagy. Autophagy can be activated during the degradation of abnormal proteins and following damage to cellular organelles (37). Additionally, autophagy was generally considered a survival mechanism; however, when damage to cells is excessive, autophagic flux can be inhibited, initiating autophagic cell death (38). In the current study, the pro-inflammatory response and autophagic activity results have a similar trend, suggesting that a potential association exists between inflammation and autophagy. Previous studies have demonstrated that autophagy was associated with innate immunity; autophagy can regulate inflammation by regulating the secretion of inflammatory mediators (39-41). Autophagy may promote inflammation in the presence of ROS-damaged mitochondria (42), which is consistent with the results of the present study. Several reports have demonstrated that abnormal autophagy in cells can lead to death $(24,43,44)$. In the present study, the cellular apoptosis assay identified Ang II-induced cell death, which was attenuated by treatment with Ator. By releasing cytochromes and proapoptotic-associated proteins into the cytosol, mitochondria serve a key role in apoptosis (45). Mitochondrial dysfunction may cause an increase in ROS, leading to cellular apoptosis $(46,47)$. In the present study, cellular apoptosis may be ascribed to a disorder of the intracellular microenvironment, including an increase in ROS, mitochondrial dysfunction and/or autophagic activity. Furthermore, Ator may attenuate these cellular responses preventing Ang II-induced cytotoxicity in HUVECs.

In the current study, the expression level of eNOS in HUVECs was evaluated. The results indicated that HUVECs expressed an abnormal level of eNOS following treatment with Ang II. Ator may be beneficial for the normal function of HUVECs as it was able to reverse the Ang II-induced effects on eNOS expression. These results were consistent with previous studies in which statins were shown to modulate the expression of endoglin, a glycoprotein strongly associated with the expression and activity of eNOS (48-50). The expression of eNOS may be involved in endothelial dysfunction (51).
It may be hypothesized that Ator modulated eNOS expression in HUVECs by regulating cellular homeostasis.

Numerous studies have demonstrated that cellular responses, including oxidative stress, apoptosis and mitochondrial dysfunction, may lead to accelerated aging $(19,52,53)$. In the current study, Ator delayed Ang II-induced cellular senescence, efficiently reversing the aging process in HUVECs and indicating a potential anti-aging activity.

The present study examined the angiogenic function of HUVECs using a tube formation assay. Ang II significantly decreased the length of the tube-like vasculature, consistent with a previous study (30). However, following treatment with Ator, the length of the tube-like vasculature increased and angiogenesis function in HUVECs was recovered. The Ang II-induced angiogenic dysfunction in HUVECs was reversed by treatment with Ator.

There were several limitations to this study. Given the limited study duration, there is a possibility that treatment with Ator may be more beneficial to HUVECs at a larger dose and/or for a longer period of time. In addition, the involvement of several signaling pathways including, the mitogen-activated protein kinase pathway, nuclear factor $\kappa$ light chain enhancer of activated B cells pathway, Rho kinase pathway and the protein kinase B pathway, require further investigation. The potential anti-aging activity of Ator should also be further evaluated.

In conclusion, the results of the present study demonstrated that Ator inhibited Ang II-induced cytotoxicity in HUVECs by modulating a series of cellular responses (Fig. 10). In general, treatment of HUVECs with Ang II caused cytotoxic effects. These cytotoxic effects were associated with an increase in ROS production and significant deficits in mitochondrial activity. These changes caused activation of the inflammatory response, autophagy and apoptosis. Treatment with Ator significantly reversed these adverse cellular responses and maintained cellular homeostasis. Furthermore, eNOS expression, which is associated with the function of HUVECs (51), was reinstated by treatment with Ator. Alteration in the cellular microenvironment ultimately leads to cell aging (54). In the current study, Ator delayed Ang II-induced aging by maintaining cellular homeostasis. Additionally, Ang II-induced dysfunction of angiogenesis in HUVECs was reversed by the addition of Ator treatment. As a lipid-lowering drug, atorvastatin can lower cholesterol in the blood by inhibiting HMG-CoA reductase; however, it may also modulate many non-lipid effects, including anti-tumor effects, and the suppression of atherosclerosis and thrombosis. These findings highlight the non-lipid effects of Ator and its potential for clinical application.

\section{Acknowledgements}

Not applicable.

\section{Funding}

No funding received.

\section{Availability of data and materials}

The analyzed datasets generated during this study are available from the corresponding author on reasonable request. 


\section{Authors' contributions}

HD and BS designed and performed the study. RD helped analyze the data. HZ directed this paper and is the corresponding author.

\section{Ethics approval and consent to participate}

Not applicable.

\section{Patient consent for publication}

Not applicable.

\section{Competing interests}

The authors declare that they have no competing interests.

\section{References}

1. Whaley-Connell A, Johnson MS and Sowers JR: Aldosterone: Role in the cardiometabolic syndrome and resistant hypertension. Prog Cardiovasc Dis 52: 401-409, 2010.

2. Touyz RM: The role of angiotensin II in regulating vascular structural and functional changes in hypertension. Curr Hypertens Rep 5: 155-164, 2003.

3. Olkowicz M, Chlopicki S and Smolenski RT: Perspectives for angiotensinprofiling withliquidchromatography/mass spectrometry to evaluate ACE/ACE2 balance in endothelial dysfunction and vascular pathologies. Pharmacol Rep 67: 778-785, 2015.

4. Gallo S, Sala V, Gatti S and Crepaldi T: Cellular and molecular mechanisms of HGF/Met in the cardiovascular system. Clin Sci (Lond) 129: 1173-1193, 2015.

5. Kawai T, Forrester SJ, O'Brien S, Baggett A, Rizzo V and Eguchi S: AT1 receptor signaling pathways in the cardiovascular system. Pharmacol Res 125: 4-13, 2017.

6. Lucas AM, Caldas FR, da Silva AP, Ventura MM, Leite IM, Filgueiras AB, Silva CG, Kowaltowski AJ and Facundo HT: Diazoxide prevents reactive oxygen species and mitochondrial damage, leading to anti-hypertrophic effects. Chem Biol Interact 261: 50-55, 2017.

7. Lim W, Yang C, Jeong M, Bazer FW and Song G: Coumestrol induces mitochondrial dysfunction by stimulating ROS production and calcium ion influx into mitochondria in human placental choriocarcinoma cells. Mol Hum Reprod 23: 786-802, 2017.

8. Meng XM, Ren GL, Gao L, Yang Q, Li HD, Wu WF, Huang C, Zhang L, Lv XW and Li J: NADPH oxidase 4 promotes cisplatin-induced acute kidney injury via ROS-mediated programmed cell death and inflammation. Lab Invest 98: 63-78, 2018.

9. Tsai CY, Chen CY, Chiou YH, Shyu HW, Lin KH, Chou MC, Huang MH and Wang YF: Epigallocatechin-3-gallate suppresses human herpesvirus 8 replication and induces ROS leading to apoptosis and autophagy in primary effusion lymphoma cells. Int J Mol Sci 19: pii: E16, 2017.

10. Tseng CY, Wang JS and Chao MW: Causation by diesel exhaust particles of endothelial dysfunctions in cytotoxicity, pro-inflammation, permeability, and apoptosis induced by ROS generation. Cardiovasc Toxicol 17: 384-392, 2017.

11. Hong S, Kwon J, Kim DW, Lee HJ, Lee D and Mar W: Mulberrofuran $\mathrm{G}$ protects ischemic injury-induced cell death via inhibition of NOX4-mediated ROS generation and ER stress. Phytother Res 31: 321-329, 2017.

12. Marchi S, Giorgi C, Suski JM, Agnoletto C, Bononi A, Bonora M, De Marchi E, Missiroli S, Patergnani S, Poletti F, et al: Mitochondria-ros crosstalk in the control of cell death and aging. J Signal Transduct 2012: 329635, 2012.

13. Zheng J, Li G, Chen S, Bihl J, Buck J, Zhu Y, Xia H, Lazartigues E, Chen $\mathrm{Y}$ and Olson JE: Activation of the ACE2/Ang-(1-7)/Mas pathway reduces oxygen-glucose deprivation-induced tissue swelling, ROS production, and cell death in mouse brain with angiotensin II overproduction. Neuroscience 273: 39-51, 2014.
14. Schachter M: Chemical, pharmacokinetic and pharmacodynamic properties of statins: An update. Fundam Clin Pharmacol 19: 117-125, 2005.

15. Yang ZX, Wang YZ, Jia BB, Mao GX, Lv YD, Wang GF and Yu H: Downregulation of miR-146a, cyclooxygenase-2 and advanced glycation end-products in simvastatin-treated older patients with hyperlipidemia. Geriatr Gerontol Int 16: 322-328, 2016.

16. Čarnická S, Adameová A, Nemčeková M, Matejíková J, Pancza D and Ravingerová T: Distinct effects of acute pretreatment with lipophilic and hydrophilic statins on myocardial stunning, arrhythmias and lethal injury in the rat heart subjected to ischemia/reperfusion. Physiol Res 60: 825-830, 2011.

17. Davignon J: Beneficial cardiovascular pleiotropic effects of statins. Circulation 109 (23 Suppl 1): III39-III43, 2004.

18. Cui W, Matsuno K, Iwata K, Ibi M, Katsuyama M, Kakehi T, Sasaki M, Ikami K, Zhu K and Yabe-Nishimura C: NADPH oxidase isoforms and anti-hypertensive effects of atorvastatin demonstrated in two animal models. J Pharmacol Sci 111: 260-268, 2009.

19. Ren C, Hu X, Li X and Zhou Q: Ultra-trace graphene oxide in a water environment triggers Parkinson's disease-like symptoms and metabolic disturbance in zebrafish larvae. Biomaterials 93: 83-94, 2016.

20. Assmus B, Urbich C, Aicher A, Hofmann WK, Haendeler J, Rössig L, Spyridopoulos I, Zeiher AM and Dimmeler S: HMG-CoA reductase inhibitors reduce senescence and increase proliferation of endothelial progenitor cells via regulation of cell cycle regulatory genes. Circ Res 92: 1049-1055, 2003.

21. Brand MD and Nicholls DG: Assessing mitochondrial dysfunction in cells. Biochem J 435: 297-312, 2011.

22. Liang X, Zhang J, Guo F, Wei L and Zhou Q: Oxidative stress and inflammatory responses in the liver of swamp eel (Monopterus albus) exposed to carbon tetrachloride. Aquaculture 496: 232-238, 2018.

23. Levine B and Klionsky DJ: Development by self-digestion: Molecular mechanisms and biological functions of autophagy. Dev Cell 6: 463-477, 2004

24. Zhang L, Wang X, Miao Y, Chen Z, Qiang P, Cui L, Jing H and Guo Y: Magnetic ferroferric oxide nanoparticles induce vascular endothelial cell dysfunction and inflammation by disturbing autophagy. J Hazard Mater 304: 186-195, 2016.

25. Zhang Q, Lai S, Hou X, Cao W, Zhang Y and Zhang Z: Protective effects of PI3K/Akt signal pathway induced cell autophagy in rat knee joint cartilage injury. Am J Transl Res 10: 762-770, 2018.

26. Chatterjee A, Black SM and Catravas JD: Endothelial nitric oxide (NO) and its pathophysiologic regulation. Vascul Pharmacol 49: 134-140, 2008.

27. Chen L, Xia W and Hou M: Mesenchymal stem cells attenuate doxorubicin-induced cellular senescence through the VEGF/Notch/TGF- $\beta$ signaling pathway in $\mathrm{H} 9 \mathrm{c} 2$ cardiomyocytes. Int J Mol Med 42: 674-684, 2018.

28. Skrzypek K, Nibbelink MG, Karbaat LP, Karperien M, van Apeldoorn A and Stamatialis D: An important step towards a prevascularized islet macroencapsulation device-effect of micropatterned membranes on development of endothelial cell network. J Mater Sci Mater Med 29: 91, 2018.

29. Nashimoto Y, Hayashi T, Kunita I, Nakamasu A, Torisawa Y, Nakayama M, Takigawa-Imamura H, Kotera H, Nishiyama K, Miura $T$ and Yokokawa R: Integrating perfusable vascular networks with a three-dimensional tissue in a microfluidic device. Integr Biol (Camb) 9: 506-518, 2017.

30. Kou B, Vatish M and Singer DR: Effects of angiotensin II on human endothelial cells survival signalling pathways and its angiogenic response. Vascul Pharmacol 47: 199-208, 2007.

31. Buharalioglu CK, Song CY, Yaghini FA, Ghafoor HU, Motiwala M, Adris T, Estes AM and Malik KU: Angiotensin II-induced process of angiogenesis is mediated by spleen tyrosine kinase via VEGF receptor-1 phosphorylation. Am J Physiol Heart Circ Physiol 301: H1043-H1055, 2011.

32. Jagadeeswaran R, Vazquez BA, Thiruppathi M, Ganesh BB, Ibanez V, Cui S, Engel JD, Diamond AM, Molokie RE, DeSimone J, et al: Pharmacological inhibition of LSD1 and mTOR reduces mitochondrial retention and associated ROS levels in the red blood cells of sickle cell disease. Exp Hematol 50: 46-52, 2017.

33. Márquez-Ramírez SG, Delgado-Buenrostro NL, Chirino YI, Iglesias GG and López-Marure R: Titanium dioxide nanoparticles inhibit proliferation and induce morphological changes and apoptosis in glial cells. Toxicology 302: 146-156, 2012. 
34. Chen L, Chen DQ, Wang M, Liu D, Chen H, Dou F, Vaziri ND and Zhao YY: Role of RAS/Wnt/ $\beta$-catenin axis activation in the pathogenesis of podocyte injury and tubulo-interstitial nephropathy. Chem Biol Interact 273: 56-72, 2017.

35. Alvarenga EM, Souza LK, Araújo TS, Nogueira KM, Sousa FB, Araújo AR, Martins CS, Pacífico DM, de C Brito GA, Souza EP, et al: Carvacrol reduces irinotecan-induced intestinal mucositis through inhibition of inflammation and oxidative damage via TRPA1 receptor activation. Chem Biol Interact 260: 129-140, 2016.

36. Levine B and Klionsky DJ: Development by self-digestion: Molecular mechanisms and biological functions of autophagy. Dev Cell 6: 463-477, 2004.

37. Yorimitsu T and Klionsky DJ: Autophagy: Molecular machinery for self-eating. Cell Death Differ 12 (Suppl 2): S1542-S1552, 2005.

38. Li C, Liu H, Sun Y, Wang H, Guo F, Rao S, Deng J, Zhang Y, Miao Y, Guo C, et al: PAMAM nanoparticles promote acute lung injury by inducing autophagic cell death through the Akt-TSC2-mTOR signaling pathway. J Mol Cell Biol 1: 37-45, 2009.

39. Deretic V, Saitoh T and Akira S: Autophagy in infection, inflammation and immunity. Nat Rev Immunol 13: 722-737, 2013.

40. Levine B, Mizushima N and Virgin HW: Autophagy in immunity and inflammation. Nature 469: 323-335, 2011.

41. Saitoh T and Akira S: Regulation of innate immune responses by autophagy-related proteins. J Cell Biol 189: 925-935, 2010.

42. Zhou R, Yazdi AS, Menu P and Tschopp J: A role for mitochondria in NLRP3 inflammasome activation. Nature 469: 221-225, 2011.

43. Vesa J, Su H, Watts GD, Krause S, Walter MC, Martin B, Smith C, Wallace DC and Kimonis VE: Valosin containing protein associated inclusion body myopathy: abnormal vacuolization, autophagy and cell fusion in myoblasts. Neuromuscul Disord 19: 766-772, 2009

44. Mishra AR, Zheng J, Tang X and Goering PL: Silver nanoparticle-induced autophagic-lysosomal disruption and NLRP3-inflammasome activation in HepG2 cells is size-dependent. Toxicol Sci 150: 473-487, 2016.
45. Yang G, Wang S, Zhong L, Dong X, Zhang W, Jiang L, Geng C, Sun X, Liu X, Chen M and Ma Y: 6-Gingerol induces apoptosis through lysosomal-mitochondrial axis in human hepatoma G2 cells. Phytother Res 26: 1667-1673, 2012.

46. Lane N: Mitochondrial disease: Powerhouse of disease. Nature 440: 600-602, 2006

47. Bouchier-Hayes L, Lartigue L and Newmeyer DD: Mitochondria: Pharmacological manipulation of cell death. J Clin Invest 115: 2640-2647, 2005.

48. Toporsian M, Gros R, Kabir MG, Vera S, Govindaraju K, Eidelman DH, Husain M and Letarte M: A role for endoglin in coupling eNOS activity and regulating vascular tone revealed in hereditary hemorrhagic telangiectasia. Circ Res 96: 684-692, 2005.

49. Shyu KG, Wang BW, Chen WJ, Kuan P and Hung CR: Mechanism of the inhibitory effect of atorvastatin on endoglin expression induced by transforming growth factor-beta1 in cultured cardiac fibroblasts. Eur J Heart Fail 12: 219-226, 2010.

50. Giordano A, Romano S, Monaco M, Sorrentino A, Corcione N, Di Pace AL, Ferraro P, Nappo G, Polimeno M and Romano MF: Differential effect of atorvastatin and tacrolimus on proliferation of vascular smooth muscle and endothelial cells. Am J Physiol Heart Circ Physiol 302: H135-H142, 2012.

51. Zemankova L, Varejckova M, Dolezelova E, Fikrova P, Jezkova K, Rathouska J, Cerveny L, Botella LM, Bernabeu C, Nemeckova I and Nachtigal P: Atorvastatin-induced endothelial nitric oxide synthase expression in endothelial cells is mediated by endoglin. J Physiol Pharmacol 66: 403-413, 2015.

52. von Muhlinen N, Horikawa I, Alam F, Isogaya K, Lissa D, Vojtesek B, Lane DP and Harris CC: p53 isoforms regulate premature aging in human cells. Oncogene 37: 2379-2393, 2018.

53. Isaev NK, Genrikhs EE, Oborina MV and Stelmashook EV: Accelerated aging and aging process in the brain. Rev Neurosci 29: 233-240, 2018

54. Moruno-Manchon JF, Uzor NE, Kesler SR, Wefel JS, Townley DM, Nagaraja AS, Pradeep S, Mangala LS, Sood AK and Tsvetkov AS: Peroxisomes contribute to oxidative stress in neurons during doxorubicin-based chemotherapy. Mol Cell Neurosci 86: 65-71, 2018. 